\title{
Prospects for the use of SMR and IGCC technologies for power generation in Poland
}

\author{
Artur Wyrwa ${ }^{1, *}$, Wojciech Suwała ${ }^{1}$ \\ ${ }^{1}$ AGH University of Science and Technology, Faculty of Energy and Fuels, Al. A. Mickiewicza 30, \\ 30-059 Krakow, Poland
}

\begin{abstract}
This study is a preliminary assessment of prospects for new power generation technologies that are of particular interest in Poland. We analysed the economic competitiveness of small size integrated gasification combined cycle units (IGCC) and small modular reactors (SMR). For comparison we used one of the most widely applied and universal metric i.e. Levelized Cost of Electricity (LCOE). The LCOE results were complemented with the results of energy-economic model TIMES-PL in order to analyse the economic viability of these technologies under operation regime of the entire power system. The results show that with techno-economic assumptions presented in the paper SMRs are more competitive option as compared to small IGCC units.
\end{abstract}

\section{Introduction}

The European Union aspires to be a world leader in sustainable energy development. It has notably committed to decrease its $\mathrm{CO}_{2}$ emissions by $20 \%$ and $40 \%$ in 2020 and 2030 , respectively in relation to 1990 level. In long term the $80-95 \% \mathrm{CO}_{2}$ reduction is foreseen by 2050 . For countries which energy systems are heavily dependent on fossil fuels such as Poland this implies ambitious efforts to transform the energy system that may include: fuels and technologies switch to less-carbon intensive ones e.g. renewable energy sources (RES) or nuclear, improving energy efficiency, use of emission reduction technologies, including capture and storage (CCS - Carbon Capture and Storage) [1]. The energy strategy of Poland assumes that in transition period that will last approximately for the next three decades and during which a new EU energy system will be developed (i.e. RES-based and more flexible due to energy storage) coal will be still a dominant fuel for power generation.

Being a country with abundant coal resources the use of domestic fuel guarantees energy security. New ways of utilisation of coal are under consideration which include i.a. coal gasification in CCS-equipped IGCC units. CCS technology involves carbon dioxide capture from flue gases and then its storage in tight underground geological structures. All stages of the process, namely capture, transport, and storage, are mastered and used commercially, but not in the power industry. Fundamental problems are the high cost of carbon capture in power plants, a significant reduction in the power plants efficiency and a social acceptance. It cannot be prejudged at present whether the CCS technology will be

*Corresponding author: awyrwa@agh.edu.pl 
commercially available for power sector in the near future since the limited progress in its development has been achieved for the last ten years. However CCS still seems to be the possible way to use fossil fuels under the stringed EU climate regime [2].

The share of coal in the Polish energy mix will gradually decrease. This will give a space for new power generation technologies such as nuclear, which has been considered in the Polish energy policy. The plan of constructing a classical nuclear power plant seems to be delayed due to problems in finding appropriate financial schemes for these highly capital intensive investments. Classical nuclear technologies include reactors with the electric capacity of $1000 \mathrm{MW}$ or more. The current investment costs estimate is ca. $5500 \mathrm{USD} / \mathrm{kW}$ (built AP1000 reactors in the USA) and $7000 \mathrm{USD} / \mathrm{kW}$ (Hinkley Point $\mathrm{C}$ in the UK) of installed power while the costs of classic coal technologies are aporox. $2500 \mathrm{USD} / \mathrm{kW}$. Such large investments, coupled with construction delays raise significantly the capital costs. The other interesting alternatives are small modular reactors (SMRs) [3, 4]. SMRs can be developed based on two mature technologies i.e. light water reactors (LWR) or a high temperature reactors (HTR). In December 2012, concrete was poured into the construction of a set of two HTR reactors for a $210 \mathrm{MW}$ electric power plant to be commissioned in 2017. The efforts have been made in the US to implement small-capacity pressurized water reactors. NuScale company plans to launch the first Integral Pressurized Water Reactor in the US in 2024, and the $600 \mathrm{MW}$ power plant built from 12 SMRs in 2025. In Europe, the biggest interest in SMRs lies in the UK.

In this paper we analysed the perspectives of the commercial application of small size IGCC and SMR power plants in Poland. For comparing the costs of different technologies we used one of the most widely applied and universal metric i.e. Levelized Cost of Electricity (LCOE). The LCOE method has been complemented by the system analysis approach in which an energy-economic model TIMES-PL was used to in order to analyse the economic viability of these technologies under operation regime of the entire power system.

\section{Description of the method}

In this chapter at first main methods used for comparison of economic competitiveness of perspective power generation technologies are briefly described. Secondly, the input data used in calculations are presented. The Chapter ends with presentation of other most critical parameters that have an impact on the results.

\subsection{Levelized Cost of Electricity}

The Levelized Cost of Electricity (LCOE) is an universal metric widely applied to compare economic competitiveness of energy technologies. It is a ratio of the sum of discounted cost components and discounted electricity generation as presented below:

$$
\begin{gathered}
L C O E=\frac{\sum_{t=T P}^{T 0}\left(N_{t}\right) *\left(1+r_{t}\right)^{t}+\sum_{t=T 0}^{T K}\left(O M_{t}+F_{t}+C O 2_{t}+L_{t}\right) *\left(1+r_{t}\right)^{-t}}{\sum_{t=T 0}^{T K} P_{t} *\left(1+r_{t}\right)^{-t}} \\
-\frac{S V_{t} *\left(1+r_{T K}\right)^{-T K}}{\sum_{t=T 0}^{T K} P_{t} *\left(1+r_{t}\right)^{-t}}
\end{gathered}
$$

The nomenclatures, superscripts and subscripts are listed in Appendix I and II. 
Determining the exact time of analysis and year "0" can be a subject of the discussion. The investment does not start with the start of the construction of the plant but often is preceded by long-term activities related to obtaining the required permits, licenses or even persuading the local community to accept the investment (Fig. 1). Although the costs of individual activities in this period may seem to be insignificant, their cumulative and discounted value may affect the overall capital costs.

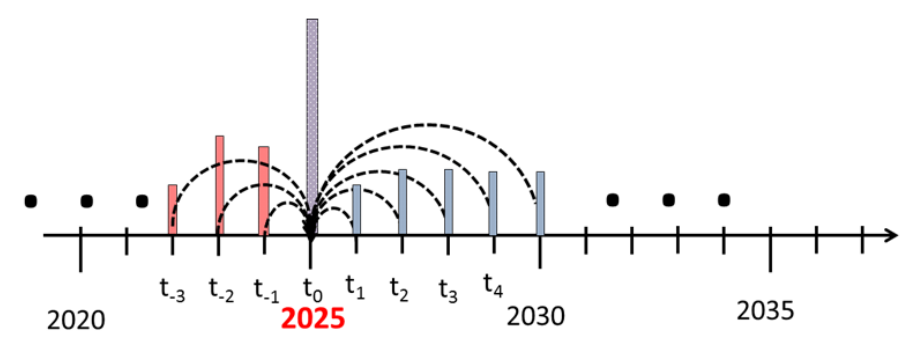

Fig. 1. Discount scheme for the year of production start (2025).

In this study we propose that year " 0 " is 2025 and this is the time by when the plants are already built and their electricity generation starts.

\subsection{Energy-economic model TIMES-PL}

TIMES is an economic model generator for energy systems. TIMES-PL is the name of the model of the Polish power system that belongs to the families of national models developed with the use of TIMES generator. It belongs to a class of bottom-up models providing a technology-rich basis for analysing energy system development over a long-term period. Its objective function represents the total costs of the supply of energy services, which are minimized by the model. In this study the mixed integer programming method was used to solve the model as for some technologies only investments in desecrate capacities were allowed. The detailed description of decision variables and equations of TIMES can be found in [5]. TIMES-PL includes all existing power plants as well as combined heat and power plants (the major plants are implemented in the model as separated units whereas renewables and small capacity units are aggregated by fuel and technology types). All technologies included in the model are characterized by a set of technological and economic parameters described in [6]. On top of these technologies two power plant types were added i.e. small size IGCC units and SMRs.

\subsection{Input data}

The main input data including costs of: power generation technologies, fuels, carbon credits are described in next paragraphs. The influence of discount rates is also discussed. For all calculations the decommissioning costs were set equal to $15 \%$ of the total investment cost for nuclear power plants and 5\% for all other technologies. It was assumed that the salvage value of technologies after reaching their lifetime was zero.

\subsubsection{Techno-economic data describing power generation technologies}

Two techno-economic datasets were prepared for calculation of LCOE and for energy system analysis with the use of TIMES-PL, respectively. In the first case all data used were 
based on [7]. The referenced paper provide an overview of region-specific costs of power technologies for many countries. As also different data sources are indicated in this paper, in our study we used the data provided by the Eurelectric. Two values of investment costs were used for SMR technology (Table 1). The lower one i.e. $3000 \mathrm{USD} / \mathrm{kW}$ is very optimistic and served as the benchmark for showing the costs reduction potential due to learning effects with aggressive investments in this technology. The other one represent the forecasted value expected in 2025 when SMRs are planned to be available commercially. Additionally, it was assumed that four SMRs will be integrated to reach the electric capacity of $600 \mathrm{MW}$.

Table 1. Techno-economic data describing technologies used for LCOE calculation.

\begin{tabular}{|c|c|c|c|c|c|c|}
\hline \multirow{2}{*}{ Technology } & $\begin{array}{c}\text { Net } \\
\text { electric } \\
\text { capacity }\end{array}$ & $\begin{array}{c}\text { Investment } \\
\text { OVN }\end{array}$ & $\begin{array}{c}\text { O\&M } \\
\text { variable }\end{array}$ & $\begin{array}{c}\text { Operation } \\
\text { hours }\end{array}$ & Lifetime & $\begin{array}{c}\mathbf{C O}_{2} \\
\text { emission }\end{array}$ \\
\cline { 2 - 7 } & $\mathrm{MW}$ & $\begin{array}{c}{[\mathrm{USD} /} \\
\mathrm{kW}]\end{array}$ & $\begin{array}{c}{[\mathrm{USD} /} \\
\mathrm{kWh}]\end{array}$ & $\begin{array}{c}{[\mathrm{hrs} /} \\
\text { year}]\end{array}$ & years & $\begin{array}{c}{\left[\mathrm{tCO}_{2} /\right.} \\
\mathrm{MWh}]\end{array}$ \\
\hline SMR6005k & 600 & 5000 & 16.0 & 8000 & 60 & 0 \\
\hline SMR6003k & 600 & 3000 & 16.0 & 8000 & 60 & 0 \\
\hline NUC1000 & 1000 & 5000 & 12.0 & 8000 & 60 & 0 \\
\hline Coal1000 & 1000 & 1900 & 5.1 & 7000 & 40 & 0.75 \\
\hline Lig1000 & 1000 & 2100 & 5.5 & 7000 & 40 & 0.8 \\
\hline CCGT300 & 300 & 1500 & 3.9 & 3000 & 25 & 0.5 \\
\hline Coal1000_CCS & 1000 & 3460 & 8.7 & 7000 & 40 & 0.1 \\
\hline
\end{tabular}

In the second case (Table 2) the data had to be adjusted to the requirements of TIMESPL as new technologies considered in this study were added on the top of those that already are implemented in the model. Also the currency differs as in case of LCOE costs were expressed in USD whereas TIME-PL uses Polish zloty (PLN).

Table 2. Techno-economic data describing new technologies analysed in this study in TIMES-PL.

\begin{tabular}{|c|c|c|c|c|c|c|c|}
\hline \multirow{2}{*}{ Fuel/technology } & $\begin{array}{c}\text { Net } \\
\text { electric } \\
\text { capacity }\end{array}$ & OVN & $\begin{array}{c}\text { O\&M } \\
\text { fixed }\end{array}$ & $\begin{array}{c}\text { O\&M } \\
\text { variable }\end{array}$ & $\begin{array}{c}\text { Efficiency } \\
\mathbf{2 0 1 5 / 3 0 / 5 0}\end{array}$ & Lifetime & $\begin{array}{c}\mathbf{C O}_{2} \\
\text { emission }\end{array}$ \\
\cline { 2 - 8 } & $\mathrm{MW}$ & $\begin{array}{c}{[\mathrm{PLN}} \\
/ \mathrm{kW}]\end{array}$ & $\begin{array}{c}{[\mathrm{PLN}} \\
/ \mathrm{kW}]\end{array}$ & $\begin{array}{c}{[\mathrm{PLN}} \\
\text { /MW] }\end{array}$ & $\%$ & years & $\mathrm{kg} / \mathrm{GJ}$ \\
\hline HC/IGCC & 205 & 14650 & 206 & 10.74 & $42.8 / 47 / 52$ & 40 & 95.9 \\
\hline HC/IGCC+CCS & 150 & 25237 & 302 & 16.21 & $31.8 / 37 / 44$ & 40 & 9.96 \\
\hline BC/IGCC & 205 & 16810 & 225 & 11.2 & $42.8 / 47 / 51$ & 40 & 99.87 \\
\hline BC/IGCC+CCS & 150 & 29460 & 348 & 17.8 & $30.6 / 35 / 42$ & 40 & 10.19 \\
\hline HC/IGCC & 600 & 8000 & 210 & 12.0 & $44 / 51 / 52$ & 40 & 94.19 \\
\hline HC/IGCC+CCS & 600 & 12360 & 294 & 33,5 & $43 / 45$ & 40 & 11.30 \\
\hline BC/IGCC & 600 & 8000 & 210 & 12.0 & $43 / 49 / 51$ & 40 & 109.08 \\
\hline BC/IGCC+CCS & 600 & 12640 & 294 & 36 & $41 / 44$ & 40 & 13.09 \\
\hline Nuclear/SMR & 600 & 18500 & 315 & 9,5 & $36 / 37 / 37$ & 50 & 95.9 \\
\hline
\end{tabular}




\subsubsection{Fuel prices}

Another parameter that has a significant impact on the competitiveness of IGCC and SMRs technologies is the fuel price. Fuel prices used for LCOE calculation are given for 2025 (year in which operation of power plants starts). TIMES-PL considers the modelling time horizon from 2011 till 2050. The prices presented in Table 3 are given for the base year i.e. 2011. In years coming after 2011 they follow the forecast presented in [8].

Table 3. Fuel prices.

\begin{tabular}{|c|cc|cc|}
\hline Fuel type/method & \multicolumn{2}{|c|}{ LCOE (2025) } & \multicolumn{2}{c|}{ TIMES-PL (2011) } \\
\hline Hard coal & 3.60 & {$[\mathrm{USD} / \mathrm{GJ}]$} & 12.8 & {$[\mathrm{PLN} / \mathrm{GJ}]$} \\
\hline Brown coal & 2.12 & {$[\mathrm{USD} / \mathrm{GJ}]$} & 7.1 & {$[\mathrm{PLN} / \mathrm{GJ}]$} \\
\hline Natural gas & 9.76 & {$[\mathrm{USD} / \mathrm{GJ}]$} & 24.0 & {$[\mathrm{PLN} / \mathrm{GJ}]$} \\
\hline Nuclear fuel & 9.30 & {$[\mathrm{USD} / \mathrm{MWh}]$} & 2.0 & {$[\mathrm{PLN} / \mathrm{GJ}]$} \\
\hline
\end{tabular}

\subsubsection{Prices of EU $\mathrm{CO}_{2}$ emission allowances}

Since 2020 electricity generators will have to fully pay for $\mathrm{CO}_{2}$ emission (in fact they will need first to purchase the EU $\mathrm{CO}_{2}$ emission allowances for emissions - EUAs on auctions). There are many studies devoted to the analysis of the evolution of EUAs prices in the short, medium and long term. As EUAs prices have a strong impact on results, two scenarios were adopted for carbon pricing in TIMES_PL (Table 4). First one, our "REF", refers to the high emission price scenario presented in [9]. The second, a "HIGH" scenario, refers to the $\mathrm{CO}_{2}$ emissions allowance prices presented in the scenario "Current Policy Initiatives" of the EU Energy Roadmap 2050 [10].

Table 3. EUAs price scenarios considered in TIMES-PL [PLN/tCO 2 ].

\begin{tabular}{|c|c|c|c|c|c|c|c|c|}
\hline Scenario & $\mathbf{2 0 1 5}$ & $\mathbf{2 0 2 0}$ & $\mathbf{2 0 2 5}$ & $\mathbf{2 0 3 0}$ & $\mathbf{2 0 3 5}$ & $\mathbf{2 0 4 0}$ & $\mathbf{2 0 4 5}$ & $\mathbf{2 0 5 0}$ \\
\hline REF & 41 & 62 & 62 & 70 & 74 & 78 & 82 & 87 \\
\hline HIGH & 41 & 62 & 95 & 132 & 165 & 202 & 206 & 210 \\
\hline
\end{tabular}

In the case of LCOE calculation the carbon price was set according to the value forecasted in the HIGH scenario for 2025 i.e. $25 \mathrm{USD} / \mathrm{t} \mathrm{CO}_{2}$.

\subsubsection{Discount rates}

A discount rate $r$ is a real rate of return on investment. It is also used for calculation of the cost of capital. The most commonly used values are: $5,8,10$ or $12 \%$, depending on the degree of investment risk. A higher rate is assumed for investments with higher risk [11]. For LCOE calculation we proposed the approach which differentiate discount rates depending on the phase of the investment. During construction, the risk is higher because there is an uncertainty about the completion date and construction costs, so the discount rate should be higher (Table 4). Investment risk is the highest for nuclear power plants because of the possibility of prolonging construction time, slightly lower for coal-fired power plants and the lowest for gas fired power plants with short construction times. When power plants start to operate the risk is much smaller and is mainly related to the variations in electricity and fuel prices as well as operational accidents. 
Table 4. Discount rates assumed for power generation technologies (\%) for construction period.

\begin{tabular}{|c|c|c|c|c|}
\hline & $\mathbf{2 0 1 7}$ & $\ldots$ & $\mathbf{2 0 2 5}$ & 2026 onwards \\
\hline SMR6005k & 10 & $\ldots$ & 10 & 5 \\
\hline SMR6003k & 10 & $\ldots$ & 10 & 5 \\
\hline Nuc1000 & 10 & $\ldots$ & 10 & 5 \\
\hline Coal1000 & 8 & $\ldots$ & 8 & 8 \\
\hline CCGT300 & 5 & $\ldots$ & 5 & 10 \\
\hline Lig1000 & 8 & $\ldots$ & 8 & 5 \\
\hline Coal1000_CCS & 8 & $\ldots$ & 8 & 8 \\
\hline
\end{tabular}

Another approach was used in TIMES-PL where the universal discount rates were used equal to $5 \%$ and $8 \%$ for all technologies in two different model runs, respectively. At first the investment costs were split into construction years based on the following formulae:

$$
F r_{t}=\int_{t+1}^{t} \frac{\sin \theta_{t}}{2} d \theta_{t}, \quad \theta_{t}=\frac{t \cdot \pi}{T c}
$$

Secondly, to costs of capital incurred during power plants construction were calculated.

\section{Results}

Calculations of LCOE metric with the use of Equation 1 gave the results presented in Table 5. As one can see, the lowest LCOE is for small nuclear reactors with a capital investment of $3 \mathrm{k}$ USD $/ \mathrm{kWe}$. However, as mentioned above, SMR6003k served as the benchmark and achieving such a low investment cost in the near future might be unrealistic. Another technology is a small reactor with a capital investment of $5 \mathrm{k} U \mathrm{USD} / \mathrm{kWe}$. The lignite-fired power plant has comparable costs to a large nuclear unit. The LCOE for hard coal fired power plant is about $20 \%$ higher than for a nuclear power plant (carbon capture and storage system raises costs further by ca. $15 \%$ ).

Table 5. LCOE calculated for different power generation technologies.

\begin{tabular}{|c|c|c|c|c|c|c|c|}
\hline Technology & $\begin{array}{c}\text { SMR } \\
\mathbf{6 0 0 5 k}\end{array}$ & $\begin{array}{c}\text { SMR } \\
\mathbf{6 0 0 3 k}\end{array}$ & $\begin{array}{c}\text { NUC } \\
\mathbf{1 0 0 0}\end{array}$ & $\begin{array}{c}\text { Coal } \\
\mathbf{1 0 0 0}\end{array}$ & $\begin{array}{c}\text { Lignite } \\
\mathbf{1 0 0 0}\end{array}$ & $\begin{array}{c}\text { CCGT } \\
\mathbf{3 0 0}\end{array}$ & $\begin{array}{c}\text { Coal } \\
\text { 1000_CCS }\end{array}$ \\
\hline LCOE & 62.80 & 47.80 & 65.42 & 77.60 & 66.48 & 127.67 & 89.83 \\
\hline [USD/MWh] & & &
\end{tabular}

Since the same overnight costs for small and large nuclear technology were adopted (SMR6005k and NUC1000) [3], the difference in favour of the former is only due to the shorter construction time and hence to the lower capital costs.

As capital expenditures for power technologies cited in the literature vary a sensitivity analysis of LCOE was performed in which the unit investment costs (OVN) were differentiated for all technologies assuming normal distribution with standard deviations estimated in [7]. The results of 250 simulation runs are presented in Fig. 2. 


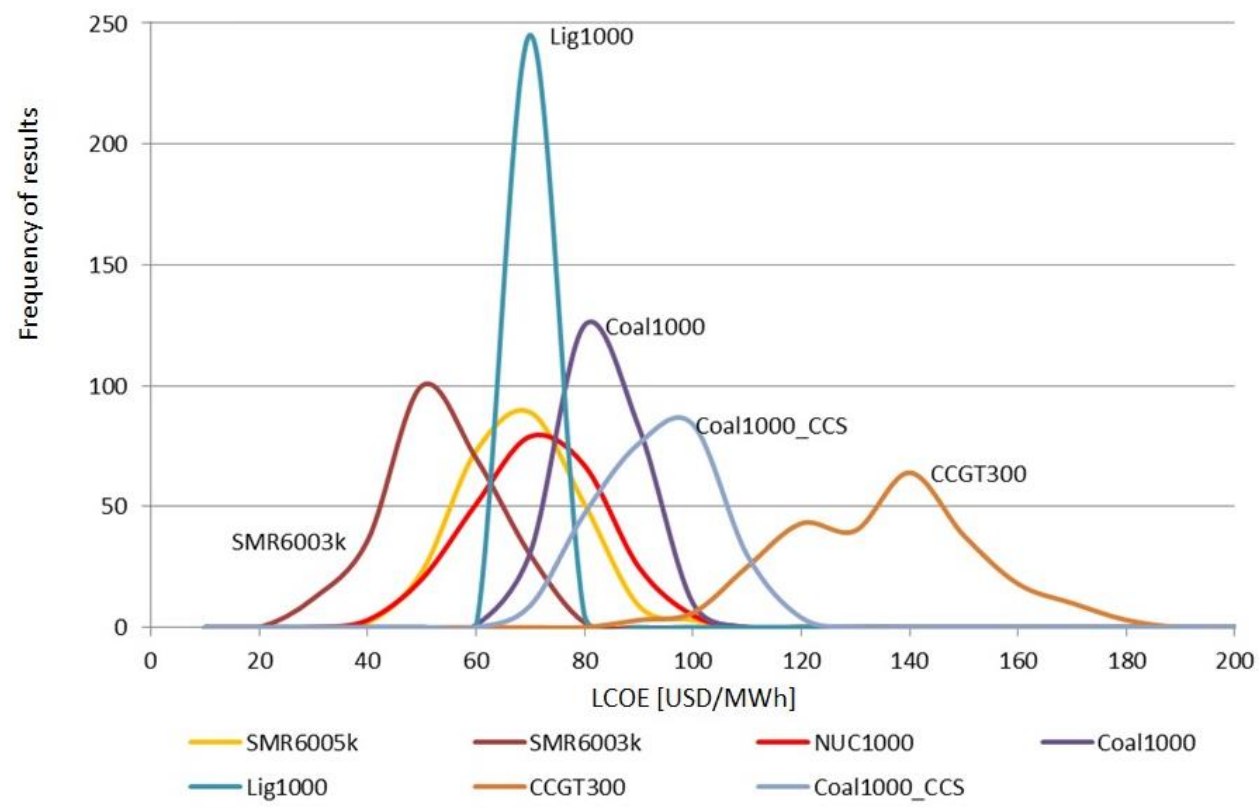

Fig. 2. Frequency distributions of LCOE caused by the change of investment costs (OVN).

The results of sensitivity analysis confirm that nuclear and lignite power plants are the most competitive. The results of TIMES-PL model runs in terms of new capacities constructed in the analysed time horizon are presented in Table 6.

Table 6. New electric capacities [GW] added by the model.

\begin{tabular}{|c|c|c|c|c|c|c|c|c|}
\hline Scenario & Technology & r[\%] & $\mathbf{2 0 2 5}$ & $\mathbf{2 0 3 0}$ & $\mathbf{2 0 3 5}$ & $\mathbf{2 0 4 0}$ & $\mathbf{2 0 4 5}$ & $\mathbf{2 0 5 0}$ \\
\hline REF & Nuclear/SMR & 5 & - & 1.8 & 2.4 & 0.6 & - & - \\
\hline HIGH & Nuclear/SMR & 5 & 0.6 & 1.2 & 1.8 & 2.4 & 3.0 & - \\
\hline HIGH & Nuclear/SMR & 8 & 0.6 & 1.2 & 1.8 & 2.4 & 3.0 & - \\
\hline HIGH & BC/IGCC+CCS & 8 & & & & 0.6 & 5.6 & - \\
\hline
\end{tabular}

One can see that results depend on the $\mathrm{CO}_{2}$ price scenario and discount rates considered. With the lower discount rate SMRs are constructed in both $\mathrm{CO}_{2}$ price scenarios. In HIGH $\mathrm{CO}_{2}$ price scenarios SMRs are constructed for both values of the discount rate and in the total maximum electric capacity allowed (the new capacity additions were constrained to reflect e.g. limitation in availability of resources, qualified constructing staff, etc.). Different results, however, were obtained for small IGCC units equipped with CCS, which have not been "constructed" by the model at all. Simulations with larger IGCC/CCS units (with lower investment costs per $\mathrm{kW}$ due to the scale effect) were done (only for one discount rate equal to $8 \%$ ) and for different $\mathrm{CO}_{2}$ price scenario. In $\mathrm{HIGH} \mathrm{CO}_{2}$ price scenario new capacities in brown-coal fired IGCC units were added by the model. The electricity generation mix for $\mathrm{HIGH} \mathrm{CO}_{2}$ price scenario is depicted in Fig. 3. 


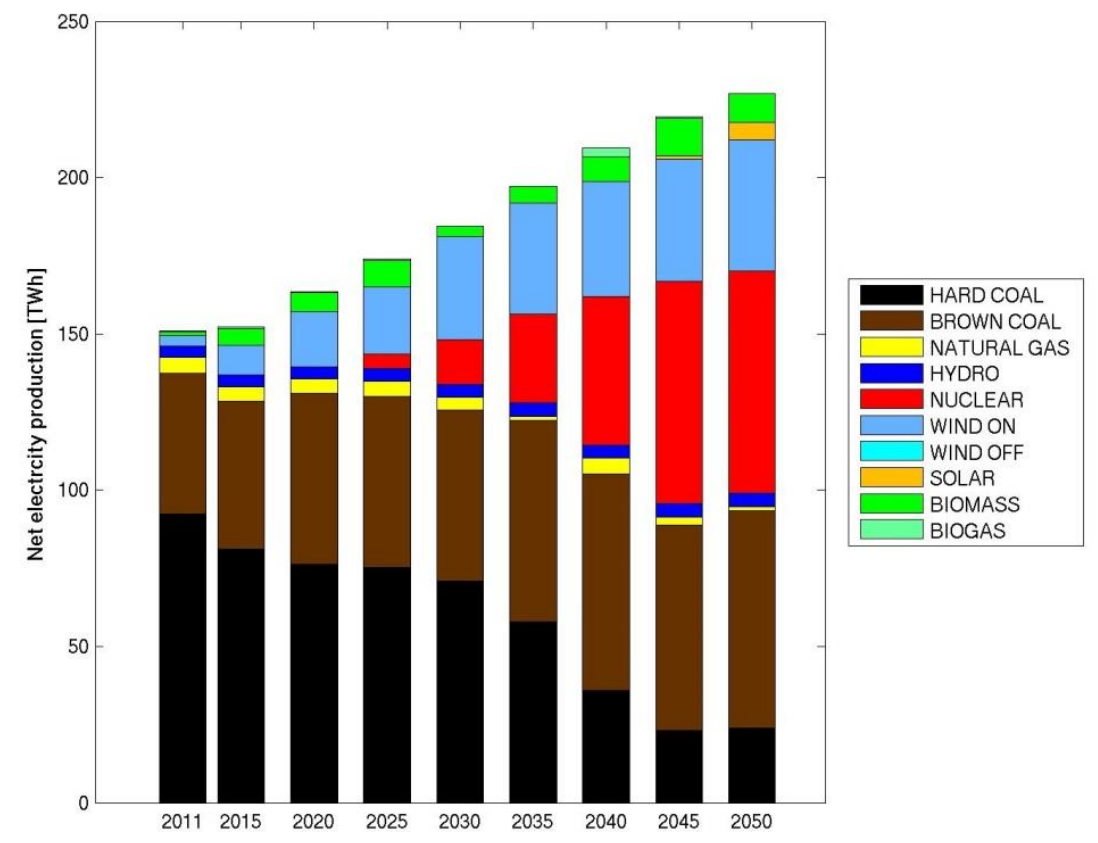

Fig. 3. Net electricity generation split into fuel types for $\mathrm{HIGH} \mathrm{CO}_{2}$ price scenario. For nuclear plants only SMR were considered.

\section{Conclusions}

Coal-fired units will still dominate power generation in Poland in the next 20-30 years. However, the relative share of coal in the Polish energy mix will gradually decrease, giving a space for new power generation technologies. We analysed the economic competitiveness of two perspective small size power generation technologies i.e. SMRs and IGCC/CCS with electric capacity of about 200 MW. These small units are based on known technologies that have been constructed with the larger capacities. On one hand downsizing to lower capacities increases investment costs per $\mathrm{kW}$ of installed power, on the other there are several economic factors such as design simplifications, accelerated learning, reduced construction time and associated risks that compensate the loss due to limited impact of economy of scale. Consequently, the costs of capital incurred during construction period are lower. Both technologies are not commercially available for power generation at present and it is forecasted that the first units can be offered in the market around 2025-2030. One should bear in mind, that both technologies can be used to deliver also other products e.g. heat [4], syngas that may influence their economic performance. However, in this study we focused on power generation. The results show that with techno-economic assumptions presented in this study and taking into account the present and perspective EU climate policy SMRs are more competitive options as compared to small IGCC/CCS units. In fact, the LCOE metric for SMRs is the lowest from all technologies considered in this study. This result is supported by results obtained from the TIMES-PL energy-economic model, which confirmed that SMRs will be able to successfully compete with other technologies once becoming a part of the power system.

This work received financial support from the statutory funding of $A G H$ (no. 11.11.210.217). 

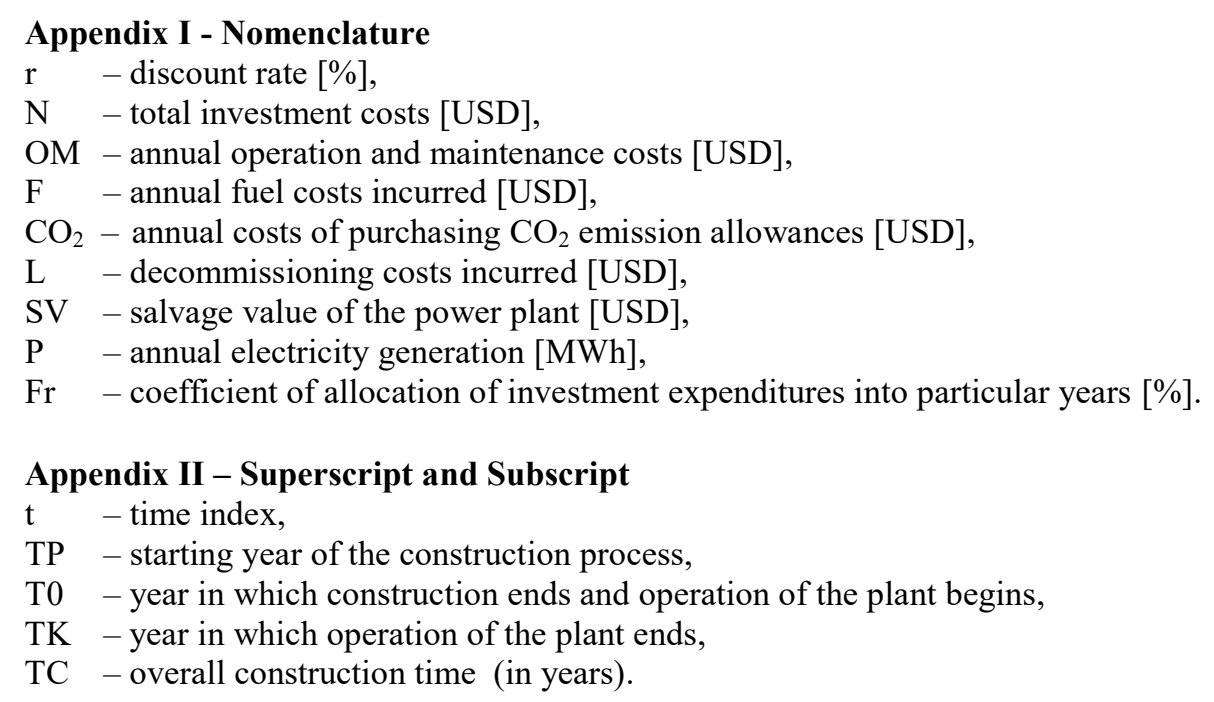

\section{References}

1. L. Gawlik, A. Szurlej, A. Wyrwa, Energy 92, 172 (2015)

2. S. Selosse, O. Ricci, Applied Energy 188, 32 (2017)

3. D.T. Ingersoll, Progress in Nuclear Energy 51, 589 (2009)

4. L. Pieńkowski, International nuclear energy congress: Warsaw, 178 (2012)

5. R. Loulou, Computational Management Science 5, 41 (2008)

6. A. Wyrwa, M. Pluta, S. Skoneczny, T. Mirowski, Lecture Notes in Computer Science 8500, 489 (2014)

7. IEA OECD, Projected Costs of Generating Electricity, Paris (2010)

8. L. Gawlik, Z. Grudzinski, J. Kaminski, P. Kaszynski, D. Kryzia, U. Lorenz, T. Mirowski, E. Mokrzycki, T. Olkuski, U. Ozga-Blaschke, M. Pluta, A. Sikora, K. Stala-Szlugaj, W. Suwała, A. Szurlej, A. Wyrwa, J. Zysk, Coal for the Polish Power Sector in the Time Perspective up to 2050 - Scenario Analysis (In Polish). Wydawnictwo Instytutu Gospodarki Surowcami Mineralnymi i Energią PAN, Katowice (2013)

9. DAS, Chancellery of the Prime Minister of Poland, Optimal Polish energy mix by 2060, Warsaw (2013) (in Polish)

10. European Commission, Energy Roadmap 2050 - Impact assessment and scenario analysis (2011)

11. H. Khatib, Energy Policy 38, 5403 (2010) 